\title{
Classroom on DEMAND: FAST ANd Fresh Video Content GENERATOR
}

\author{
$P$. Kanthamanon, $W$. Chutimaskul and V. Vanijja \\ School of Information Technology, King Mongkut's University of Technology Thonburi, Thailand \\ prasert@sit.kmutt.ac.th,wichian@sit.kmutt.ac.th and vajirasak@sit.kmutt.ac.th
}

\begin{abstract}
The Classroom on Demand (CoD) is a classroom video recording and streaming system that allows the students to revise their class contents. CoD is a tool to improve the effectiveness of the study; especially for those contents that change at a fast pace like information technology. All the classrooms of the School of Information Technology, KMUTT are equipped with the CoD system. In this paper we present the overall system architecture along with the teaching pedagogy used. Some statistical data is also presented for the entire system.
\end{abstract}

Keywords: video on demand, classroom on demand, video streaming, automated recording system

\section{INTRODUCTION}

Due to the rapid proliferation of high speed broadband Internet services recently, there has been a greater demand in the use of video on demand $(\mathrm{VoD})$ technology, that is commonly employed in homes, offices and educational institutes for solving various purposes. For educational institutes, online learning is an application of the $\mathrm{VoD}$ that allows the learner to study outside the classroom. Classroom video is the video clip that is recorded in the classroom while the lecturer is teaching. These videos are stored in a server as a video library. The students can choose any videos they desire to from the video library and view them on any device. This system is called the "Classroom on Demand (CoD)" system.

This Classroom on Demand (CoD) system was first developed in 2002 and primarily used for video recording and streaming purposes. The basic aim of the CoD system is to allow the students to review the contents of their classes at home. For any particular topic, three previous semesters' classroom contents are stored in the school's server. The students are allowed to access the earlier semester class contents before the course starts in the current semester. The system also allows the lecturers to post the class materials and assignments for the students.

The main function of the system is to record all the lectures taking place in all the classrooms of the School of
Information Technology (SIT), King Mongkut's University of Technology Thonburi (KMUTT), Thailand. The first version of $\mathrm{CoD}$ was an all manual video recording system. Every classroom was equipped with one video camera and one personal computer. The picture and voice of the lecturer and slides on the projector screen were recorded with the camera. All recorded videos were manually synchronized with MS PowerPoint Slide using MS Producer software [1]. The slides and the synchronized videos were then streamed over the Internet to the students' computer at their homes. The video was available only on a specific browser.

The new version of the $\mathrm{CoD}$ was implemented in 2015. It is a fully automated classroom recording system that was developed by the faculty and undergraduate students as a capstone project. Thorough testing of the system was done by the staff and students of the school as a practical case study. Since then the capstone project has spun off as a commercial product named "Oliv" [2].

\section{RELATED WORKS}

The Echo360 [3] is an example of a well-known solution for classroom recording. But the system is expensive and does not provide a centralized control.

Nukoolkit et. al [4] analyzed the exploratory data and web $\log$ of our previous $\mathrm{CoD}$ system to discover the students learning patterns. They performed a hit analysis in terms of the number of access hits and unique user hits. Many indicators were extracted by normalizing the total access hits with the number of unique user hits. As a result of the study, the lectures can gather an indirect teaching feedback from their students' study behavior through the CoD. Another interesting observation was made through the study. Some students tried to access the videos of courses that were not available for the current semester. The university used this information to determine which courses the students were most interested in, and ultimately made a decision to open those courses to serve their needs. 


\section{SYSTEM ARCHITECTURE}

To automate the recording process, a "recording box" is equipped into every classroom. The pictures of the computer screen, desktop visualizer and the lecturer voice are recorded and stored into the recording box in a High Definition (HD) format (720x1080px). Camera that captures the lecturer's movement is installed in some classes depending on the classroom size and design. The video streams from all the (maximum) four sources are recorded simultaneously.

An accompanying "web-based scheduling software" has also been developed that remotely controls all the recording boxes present in the different classrooms. The scheduling software is pre-configured to monitor the boxes and load the specific videos to the video encoding servers

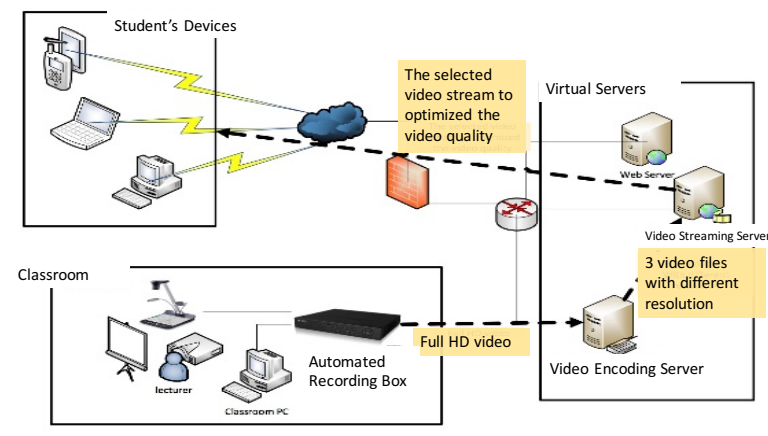

Fig. 1. CoD system diagram

After recording the videos of the scheduled classes in HD format, they are sent to a "video encoding server". The encoding server converts the videos into three different independent resolution video streams. This makes the entire system flexible because depending upon the type of mobile device and available network conditions a particular video resolution can be chosen which gives the maximum viewing satisfaction. The minimum bandwidth that is required to watch the lowest resolution video in the $\mathrm{CoD}$ system is $360 \mathrm{Kbps}$.

There are thirteen classrooms in SIT that are equipped with the recording box. For each classroom the videos are recorded from $8.00 \mathrm{am}$ to $9.00 \mathrm{pm}$ every day. The service level agreement (SLA) of the system ensures that each classroom video is posted on the web within $24 \mathrm{hrs}$. after the class ends. The system diagram is shown in the Fig. 1.

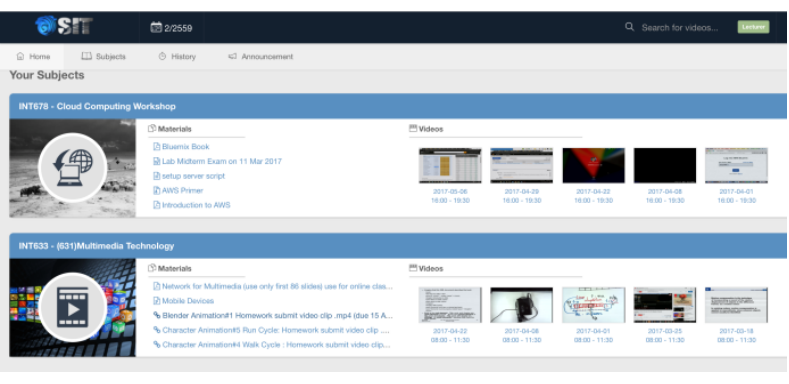

Fig. 2. CoD: Personalized course list

\section{USER INTERFACE}

The user interface of the CoD is designed based on the assumption that the users may access the video contents over a variety of device platforms, screen form factors and network connection speed. The end user interface is a responsive web application that allows the users to access the video contents through a simple web browser. The web application has been personalized based upon the user profile. The courses that the users are enrolled in will be shown on the personalized course list as shown in Fig. 2.

In each course page, the classroom videos with preview are listed, as shown in Fig. 3.

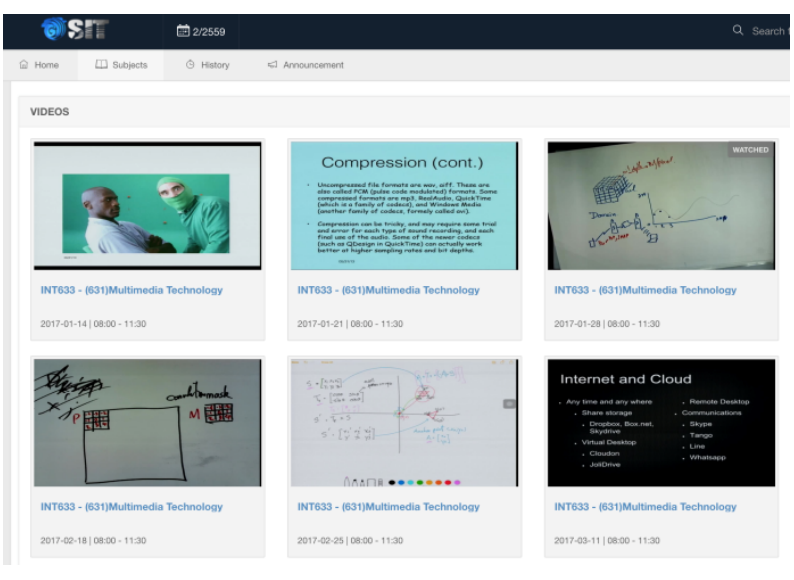

Fig. 3. CoD: Classroom list 


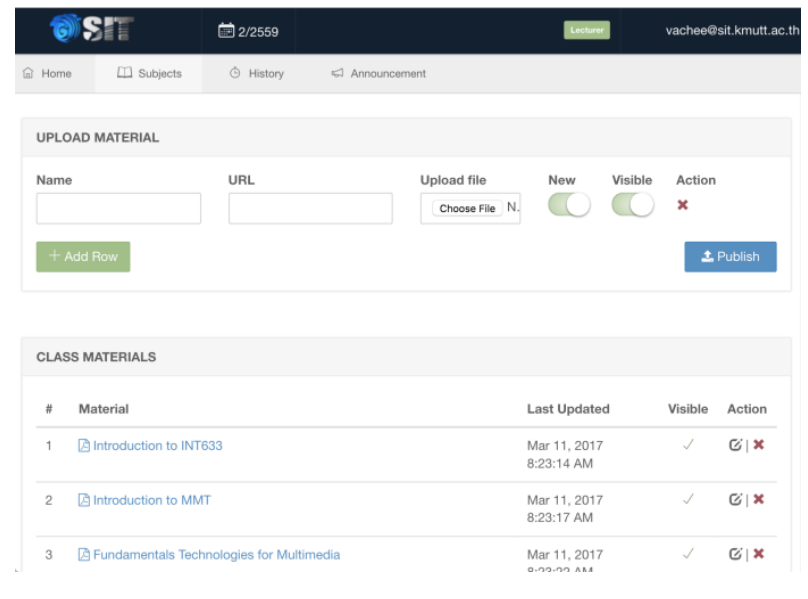

Fig. 4. CoD: Class materials list

The instructor is able to upload the class materials at the bottom part of the course page, as shown in the Fig. 4. The students can download and use the materials in the class.

With the HTML 5.0 technology [5], the students are able to review their classes via any mobile device with a responsive web interface. The new system reduces time and resources to produce the classroom video contents. The students are allowed to leave questions and comments to the lecturer and other students to share their knowledge and opinions.

With some customization, The CoD is able to integrate with other learning management system and massive online open courseware management system such as Moodle [6] or Edx[7].

\section{USERS DEFINITION}

The students of the School of Information Technology (SIT) are the main users of the CoD system. SIT has two undergraduate programs and four postgraduate programs. The total number of students enrolled in the undergraduate and postgraduate programs is 586 and 548 respectively. Most of the postgraduate students are parttime students. They work full time during the weekdays and study during the evening or on weekends. In some cases, the $\mathrm{CoD}$ can be used by the lecturers as content reviewing assignments also. However, most of the students use the $\mathrm{CoD}$ to review the class contents before the examination. The access logs are used to analyze the usage pattern. By the way, the students have to attend not less than $80 \%$ of the physical classes base on the university regulation.

\section{PEDAGOGY}

There are several methods to use the recorded videos in the learning pedagogy. These are three sample scenarios that are applied to the students.
1. The simplest method to use the CoD is to use it as a personal tutor. Most of the student login to the system and watch the videos, a few weeks before the examination. With the text book and provided materials, the students have enough resources to prepare for their examination.

2. All the classrooms of the school are equipped with the CoD system. The lecturers can use them as teaching tools in both active and passive style. Since the videos of the previous semester are stored in the system; hence the lecturer may assign the students to watch the fundamental content already available and then do an advance group discussion in the class.

3. The system allows the students to be able to access the classes' contents for which they are not enrolled also. The school offers more than 100 courses in a semester. The student may be assigned to revise the content of the other fundamental subjects in order to prepare for the advanced subjects. This scenario is especially applicable for the graduate students who need to update to new technology before beginning with the advanced classes.

\section{RESULTS: SYSTEM USAGE}

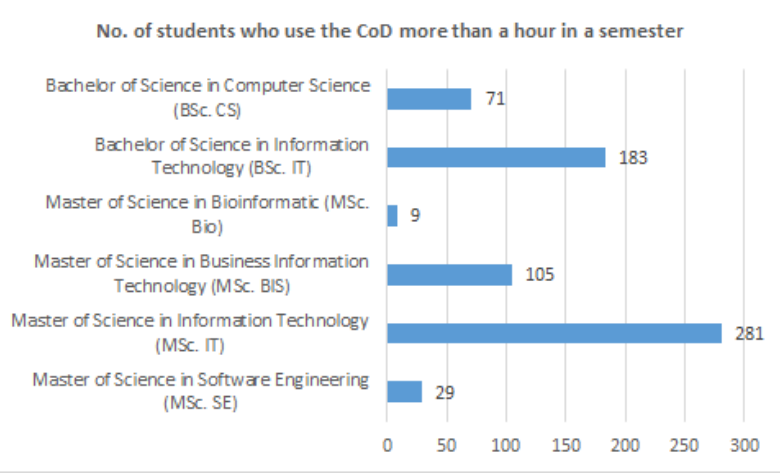

Fig. 5. No. of students who use the CoD more than an hour in a semester

The CoD system is used by more than 800 uniquestudents (from both undergraduate and postgraduate programs) which signed in to the system in the latest semester. The number of the students who use the CoD at least an hour in the semester are shown in Fig. 5.

$65 \%$ of the users are postgraduate students who are part-time students. They use the $\mathrm{CoD}$ as a personal tutor to prepare for the examination. For the latest semester, $10 \%$ of all the students used the CoD for more than 50 hrs. $41 \%$ of the postgraduate students used CoD for more than $10 \mathrm{hrs}$. in the semester. $71 \%$ of the students used the 
CoD more than an hour in the semester. The summary of students' usage times categorized by curriculums are shown in Fig. 6

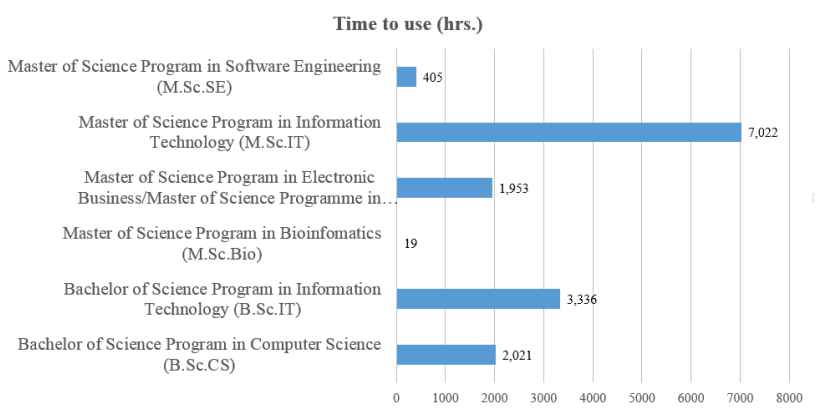

Fig. 6. Students' usage time (in hours)

The results show that $1.6 \%$ of the graduate students who use the system for more than $100 \mathrm{hrs}$. in the semester has an average GPA of more than 3.40, while the threshold value of the GPA is fixed at 3.0.

\section{CONCLUSION}

CoD is a tool to improve the teaching and learning effectiveness. The lecturers use the videos of the previous semester classes to improve their teaching technique. Lecturers and students may use other social media channel such as "Line" Application [8] or "Google Plus" to interact and share the knowledge.

Sometimes there are isolated complains from the students about the missing video and voice parts for some of the classes due to the cabling and human errors. Still the CoD which is embedded into all the classrooms of the school enable all the lecturers and students to be involved with the system closely.

It is incorrect to conclude that the $\mathrm{CoD}$ is able to improve the GPA of the students. However, we can claim that the $\mathrm{CoD}$ is an effective knowledge management tool for the school.

\section{References}

[1] Microsoft Corporation, Microsoft Producer for Power Point 2003, 2003, Available as of May 19, 2017 from https://www.microsoft.com/enus/download/details.aspx?id=1594

[2] Softever, Oliv,2017, Available as of May 19, 2017 from https://www.facebook.com/Softever-306582356025014/.

[3] Mark, Kai Pan; Vogel, Douglas R.; and Wong, Eva Y. W., "Developing Learning System Continuance with Teachers and Students: Case Study of the Echo360 Lecture Capturing System," in Proc. Pacific Asia Conference on Information Systems, PACIS 2010, (Taipei, Taiwan, 9-12 July 2010), pp. 1727-1734, 2010.

[4] C. Nukoolkit, P. Chansripiboon, S. Sopitsirikul, "Improving University e-Learning with Exploratory Data Analysis and Web Log Mining", in Proc. The $6^{\text {th }}$ International Conference on Computer Science and Education (ICCSE 2011), (Singapore, 3-5 August 2011), 2011.

[5] Mohammad Ubaidullah Bokhari ; Hassan Faisal Aldheleai ; Yahya Kord Tamandani, " Building better E-learning environment using HTML5," in Proc. 2016 3rd International Conference on Computing for Sustainable Global Development, INDIACom 2016, IEEE, (New Delhi, India, 16-18 March 2016, pp. 3959 - 3965 , 2016

[6] Linawati, Nmae Dewi Wirastuti, G. Sukadarmika, "Adaptive online learning design using Moodle," in Proc. 2016 International Conference on Smart Green Technology in Electrical and Information Systems, ICSGTEIS 2016, IEEE, (Bali, Indonesia, 6-8 Oct. 2016), 2016

[7] Héctor J. Pijeira Díaz, Javier Santofimia Ruiz, José A. Ruipérez-Valiente, Pedro J. Muñoz-Merino, Carlos Delgado Kloos, " Using Video Visualizations in Open edX to Understand Learning Interactions of Students," in Proc. 10th European Conference on Technology Enhanced Learning, EC-TEL 2015, (Toledo, Spain, September 15-18, 2015), pp. 522-525, 2015

[8] Naver Corporation, Line: Free calls \& Messages, 2015, Available as of May 19, 2017 from https://line.me/en/ 